\title{
Hidramnios Agudo de Origen Luético tratado con éxito
}

\author{
Por el doctor Fennando Mera González \\ Profesor Encargado de Obstetricia de la Universidad Nacional.
}

El exceso de líquido amniótico durante la gestación reconoce diversas causas provocadoras de la afección, y su carácter patológico está condicionado a la distensión permanente de las paredes uterinas.

El origen normal del líquido amniótico parece ser el matcrno por selección del epitelio amniótico placentario y funicular, con posible aumento por secreción urinaria o por secreción dérmica fetal.

La frecuencia con que experimentan las embarazadas este aumento de líquido es de un caso por cada 200 embarazos, y la cantidad hallada es, para unos autores, hasta de 20 litros y para De Lee, de 8 como máximo. En las multíparas, es de mayor ozurrencia.

Favorecen la aparición del hidramnios: 10-Las malformaciones fetales, y principalmente las onginadas por la falta de oclusión de las cavidades, como sucede en el labio leporino, la anencefalia, la hidrocefalia, la ectopía vesical y la cspina bífida, que provocan una trasudación serosa exagerada $2^{\circ}-$ Las alteraciones circulatorias fetales, que motivan estancamiento venoso seguido de edema y exudación, con mayor eliminación renal, seguida de aumento en el volumen del líquido amniótico, como sucede en la estenosis del cordón umbilical y de la aorta, en la estenosis del conducto de Bottalli, en las cardiopatías, en las cirrosis hepáticas y en la neumonía blanca específica; 3?-Las deformaciones fetales, sobre todo las ocasionadas por la comunicación entre el conducto cefalo-raquídeo y la cavidad amniótica; 40.-Las lesiones sobre los anexos fetales, como inflamaciones del amnios por focos sépticos diversos, los edemas placentarios, las degeneraciones fibro grasosas de la placenta, las infecciones de la decidua materna, y de los lagos interplacentarios y la endarteritis y tromboflevitis del cordón umbilical; 50-Los edemas gravídicos por el desequilibrio acuoso y salino que experimenta el organismo materno y que está subordinado al trastorno endocriniano; 6\%-Las entidades patológicas maternas, como la diabetes, la leucemia, las neumopatías, nefropatías y cardiopatías, que modifican la circulación normal y alteran la producción o falta de reabsorción del líquido en el epitelio am- 
niótico; 70-El embarazo gemelar univitelino, por la mayor actividad circulatoria del feto transfundido con mayor eliminación renal, y $8^{\circ}$ - La sífilis materna, por la provoaación de amniotitis con aumento de secreción de líquido, y por trastornos infecciosos que lesionan los vasos del cordón repercutiendo sobre la permeabilidad capilar con lesión del hígado, el bazo, el pulmón y el corazón fotales.

En la experiencia clínica que a continuación relato se pudo apreciar fácilmente la sintomatología predoninante del hidramios agudo y solamente el éxito logrado con el tratamiento patogénico y sintomático la hace interesante. La etiología sifilítica del hidramios pudo establecerse por la positividad en las reacciones serológicas y por el resultado satisfactorio con que la enferma respondió a la medicación antiespecífica que culminó con un parto a término, previa inducción del trabajo.

Histonia No. 692.-N. T., 31 años.

Diagnóstico: Hidramnios agudo. Lúes.

Antecedentes personales: anginas de repetición.

Menarquía a los 14 años. Ciclo de 30 días con duración de 3 días.

Antecedentes obstétricos: Tres embarazos normales, con partos normales a término y fetos vivos.

Embarazo actual.- Ulltima menstruación el 10 de octubre de 1950 . El cmbarazo ha evolucionado con náuseas, acedías, constipación intestinal y cdomass en los miembros inferiores.

Examen general: Piel sana. Senos normales. Pared abdominal hipertónica. Corazón normal. Pulso de 86 por minuto. Presión arterial de 120 x 80 . Pulmones: matidez de las bases, con abolición de las vibraciones vocales y disminución del murmullo vesicular.

Dientes incompletos y en mal estado. Lengua saburral. Amígdalas crípticas.

Aparato digestivo: Antecedentes de litiasis biliar e intolerancia a las grasas. Examen obstétrico: Pared abdominal con tonicidad aumentada. Embarazo de 5 meses por la fecha de la amenorrea. Altura del útero de 32 centímetros. De consistencia dura, forma normal, superficie régular y dirección longitudinal; hay circulación colateral abdominal.

Por la tensión a que se encuentra el líquido dentro de la cavidad uterina, so hace imposible precisar la situación y presentación fetales. La auscultación de los ruidos cardíacos fetales es impusible.

Pelvimetría: Bicspinoso 24 cts. Bisilíaco 271/2 cms. Bitrocantérco $32 \mathrm{cms}$. Baudcloque 21 cms.

La enferma ingresa al servicio con el abdomen prominente. Dice que desde hace 15 días nota aumento exagerado y rápido del perímetro abdominal. Al examen general se aprecia una matriz cuya altura no corresponde a la edad probable del embarazo que debió ser de 5 meses por la fecha de la amenorrea. Hay sensación de onda líquida en el contenido uterino. El borde inferior del hígado 
esta recilazado hacia arriba por sobre el reborde costal. En el examen pulmonar se aprecia macisez de las bases, con disminución del murmullo vesicular y estertores mucosos.

Marzo 31 de 1950. Se le hizo una punción en la línea media de la pared abdominal, previo cateterismo de la vejiga, extrayéndosele fácilmente $400 \mathrm{c}$. c. de líquido amniótico.

Abril $1^{0}$ de 1950. La paciente experimenta disnea, dolores abdominales irradiados a la región lumbar y la compresión que ejerce el útero sobredistendido molesta en grado sumo a la enferma. En estas condiciones se le practica una nueva punción abdominal en el punto medio, entre el ombligo y el borde superior pubiano, para extraer mayor cantidad de líquido amniótico y dejar la matriz con una altura que corresponda a la verdadera edad de gestación. La cantidad de líquido extraída en esta punción fue de unos $800 \mathrm{c}$. c.

Abril 2 de 1950. La enferma mejoró notablemente. Desaparecieron los dolores abdominales y la disnea. La altura uterina es de $20 \mathrm{cms}$. Se oyen los ruidos cardíacos fetales y se percibe el feto en situación longitudinal y presentación cefálica derecha móvil por sobre el estrecho superior.

Se le ordenan exámenes serológicos para lúes y se prescribe tratamiento sedante de la musculatura uterina, para prevenir el aborto.

Se ordenó Progesterona de 10 mgrs. I ampolleta intramuscular diaria durante 10 días, enemas calmantes a base de cloral y láudano, soluciones dextrosadas al $20 \%$ ampolletas de 20 c. c. cada 8 horas, diuréticos mercuriales (Esidron) vía intramuscular, 1 ampolleta diaria, acidificantes de la orina (cloruro de amonio) 3 grs. diarios en cápsulas de 0.50 ctgrs., para activar la acción diurética de los mercuriales.

La enferma, con el tratamiento establecido, continúa mejorando.

Abril 3 de 1950. Reacción de Kahn: positivo total. Reacción de Mazzini: Positivo débil. (Instituto de Protección Materna e Infantil).

Reacción de Wassermann: positivo. Reacción de Kahn: positivo. (Laboratorio Samper Martínez).

Con los resultados de laboratorio que denotaban una sífilis materna, se le estableció el tratamiento antiluético.

Penicilina potásica: 5.000 .000 como dosis total. 50.000 unidades cada tres horas vía intramuscular.

Mafarside: 10 ampolletas dosis total. Una ampolleta de 0,04 ctgrs. diaria vía endovenosa.

Bismuto de 0,20 ctgrs., una ampolleta diaria vía intramuscular profunda. 6 ampolletas como dosis total.

Exámenes de Laboratorio.-Análisis de sangre (abril 31 de 1950).

Hematíes 4.420 .000 por $\mathrm{mm}^{3}$. Leucocitos 7.400. Hemoglobina $90 \%$.

Valor globular 1-02.

Polimorfonucleares neutrófilos $68 \%$. Eosinófilos $1 \%$. Linfocitos pequeños $29 \%$. Grandes mononucleares $2 \%$.

Análisis de sangre (abril 5 de 1950). Indice ictérico 4 unidades. 
Azohemia y glicemia (marzo 31). Azohemia 23 mgrs. por ciento. Glicemia 0.70 grs. por mil.

Análisis parcial de orina (marzo 31 de 1950).

Ligeras huellas de albúmina. Sedimento: moco xxx. Leucositos xx. Cólulary epitcliales $\mathrm{x}$.

Serología (abril 13 de 1950). Después del tratamicnto.

Wassermann, negativo total. Reacción de Kahn, positivo.

Abril 29 de 1950. Se le da salida a la paciente por mejorar el estado de s! salud. El feto está vivo en presentación cefálica de vértice derecha, móvil. La altura uterina es de $24 \mathrm{cms}$.

Sin embargo se le aconsejan los controles periódicos a la enferm? nara seguir de cerca la evolución patológica del embarazo hasta la fecha de salidia.

En los exámenes clínicos, que se efectuaron mensualmente hasta su reingreso al hospital, ya àl término de la gestación no se observó anormalidad alguna en los últimos cuatro meses de embarazo. Por el contrario, hubo necesidad de ordenarle nueva hospitalización en el servicio de maternidad del Profesor Rodríguez Aponte (Instituto de Protección Materna e Infantil), para provocar el trabajo de parto por presumirse la prolongación en el tiempo de gestación.

Julio 18 de 1950.-Examen obstétrico: Multigestantes a término, feto único, situación longitudinal, presentación cefálica de vértice derecha, insinuada. Feto vivo. No está en trabajo.

Julio 19 de 1950. Se le ordena, para inducir el parto, lo siguiente: Enema cvacuador con 1 litro de solución jabonosa y 500 c. c. de dextrosa al 10\% con 3 unidades de pitozín y 30 gotas por minuto vía endovenosa.

Julio 19 de 1950. 23:10 horas. T. V. Vulva, vagina y perineo normales; cuello central, largo, grueso, blando con 3 cms. de dilatación, membranas rotas, presentación en OIDA encajada.

Se le retira la solución dextrosada con pitocín por encontrarse en trabajo franco, con contracciones regulares de buena intensidad.

Dosis total inyectada de la solución 350 c. c.

Julio 20 de 1950. Expulsión del feto a la 1:25 horas. Sexo masculino, res piración espontánea del niño al nacer. Expulsión de la placenta a las 1:30 horas, de manera espontánea y sin hemorragia.

Peso del niño: 3.500 grs. Talla $50 \mathrm{cms}$. Peso de la placenta 760 grs. Longiutud del cordón $60 \mathrm{cms}$. Inserción paracentral.

No hubo lesiones maternas consecutivas al parto ni se encontró macrosiópicamente nada patológico en los anexos o en el recién nacido.

El puerperio transcurrió dentro de los límites de la normalidad y la paciente sale por curación del hospital el día 28 de julio de 1950.

En la historia clínica del niño hay la siguiente anotación hecha por el jefe de clínica de sala-cuna: "No hay signos de sífilis en el niño. Debe advertirse a la madre que lo traiga personalmente a la consulta externa para control". 
Con la anterior descripción clínica se comprucba que la paciente sufrió de un hidramnios agudo, aparecido en el quinto mes de gestación, época del cmbarazo en que se presenta con mayor frecuencia el aumento patológico del líquido amniótico, en sus formas agudas.

El aumento del volumen uterino, con sobredistensión de las paredes, provocaba dolores abdominales con diferentes irradiaciones a los muslos y a la re gión lumbar, y la disnea y congestión de las bases pulmonares era el resultado de la comprensión ejercida por el útero aumentado de tamaño sobre las vísce. ras vecinas.

El tratamiento antiespecífico prescrito surtió rápidamente sus efectos, normalizando el funcionamiento del epitelio amniótico e impidiendo la superpro ducción de líquido, en orden al nacimiento de un feto vivo sin signos aparentes de sífilis congénita. La medicación sedante de la musculatura uterina impidió la excitación de la fibra y ayucó a la continuidad del cmbarazo sin que se pre. sentaran el aborto o el parto prematuro. La derivación urinaria por los mercuriales colaboró en la eliminación de los líquidos orgánicos en exceso. Las punciones que se realizaron a través de la pared abdominal provocaron la salida del líquido amniótico, disminuyendo y normalizando el volumen del útero, con la desaparición de los fenómenos comprensivos y dolorosos que causaban la sobredistensión de la matriz grávida.

El éxito logrado con esta enferma se debió única y exclusivamente a que se descubrió y trató en forma oportuna y conveniente la sífilis determinante del hidramnios. No ocurre lo mismo cuando el aumento del líquido amniótico, por deberse a causas de compleja etiología, difícilmente puede combatirse con base en el tratamiento meramente sintomático de las manifestaciones patológicas.

\section{BIBLOGRAFIA}

W. Stocckel. Tratado de Obstetricia. Editorial Modesto Uson. Valencia, España, 1945. Nubiola Zárate. Tratado de Obstetricia. Editorial Labor, 1951.

J. Moragues Bernat. Clínica Obstétrica. Editorial El Ateneo, 1946.

De Lee Greenhill. Principios y práctica de Obstetricia. Utea, 1945.

Maygrier y Schwaab. Obstetricia. Espasa Calpe, S. A., Madrid, 1943. 